Vickers) and A. H. Beck (Standard Telecommunications Laboratories, Ltd.) described cathodes of this type, formed by mixing $30-40$ parts by weight of carbonate with $70-60$ parts of nickel powder, pressing and sintering. Dr. Dodds adds as reducing agent $0 \cdot 1$ per cent silicon, and presses at 10 tons/in. ${ }^{2}$. Mr. Beck uses 1 per cent zirconium hydride as reducing agent, and presses at 80 tons/in. ${ }^{2}$. His study of the work function has indicated that the activated cathode is nickel with 70 per cent of the surface covered with barium. The temperature coefficient of the work function is $1.4 \times 10^{-4}$ eV./deg. C.

C. P. Lea-Wilson (Services Electronics Research Laboratory, Harlow) described a high-temperature magnetron cathode which emits from thorium-ontungsten. This again is formed by pressing and sintering, but employs either thorium oxide or thorium metal (about 2 per cent) mixed with tungsten carbide and tungsten. With thoria, gas is liberated over a long period of operation, and about 10 per cent of carbide is necessary to obtain emission. The thorium gives rapid outgassing and activation, and is to be preferred. In the discussion, Mr. Lea-Wilson said that the carbide is desirable even when thorium is used, possibly because it minimizes surface oxidation. There is no information as to whether thorium carbide is formed. The cathode gives a pulsed emission of 20 amp. $/ \mathrm{cm}^{2}$ at about $1,700^{\circ}$ C., and a number of valves have been operated satisfactorily for more than a thousand hours.

Another high-temperature cathode using lanthanum boride as the emitter was described by B. N. Watts (British Thomson-Houston Co., Ltd., Rugby). This is formed by reaction of metal and boron in hydrogen at $1,400^{\circ} \mathrm{C}$., and is either painted and sintered on a tantalum filament, or pressed, sintered, machined and heated indirectly. It is activated at $1,600^{\circ} \mathrm{C}$. and gives 1 amp. $/ \mathrm{cm}^{2}$ at $1,400^{\circ}$ C., the d.c. and pulsed emission being equal. No long-life test information is yet available.

Finally, P. O. Hawkins (Services Electronics Research Laboratory, Baldock) described an oxide cathode in which the normal disadvantages are overcome by applying the coating on the inner surface of a hollow box, and extracting the electrons through a small hole. From a hole $\frac{1}{3} \mathrm{~mm}$. diameter, spaced $2 \mathrm{~mm}$. from the anode, the current is very small below $920^{\circ} \mathrm{C}$. At high temperatures the current, increases at first rapidly with voltage, and then linearly and less rapidly. It exceeded 50 m.amp. at, an anode voltage of $5 \mathrm{kV}$. at $1,230^{\circ} \mathrm{C}$. This current if uniform over the hole would be $60 \mathrm{amp} . / \mathrm{cm} .{ }^{2}$; but, in fact, the beam is found to be hollow, and the current for varying hole size varies with the perimeter. The mechanism is not understood.

In discussion, Dr. D. Gabor suggested that Mr. Hawkins's cathode contains a plasma from which electrons emerge with high velocity, and the latter agreed that it does not appear to contain an electron gas at the cathode temperature. Dr. P. N. Daykin asked whether $n$ small holes would multiply the emission, and was told that this is so, giving an $n$-fold multiplication until the hole spacing becomes of the order of the hole diameter. M. E. Haine said that the beam current density per unit solid angle has a definite limit, so that a quotation of amp. $/ \mathrm{cm}^{2}$ can be misleading. In reply to a remark by Dr. O. Klemperer, Mr. Hawkins said that low-voltage measurements have not been made. Questioned about secondary emission, Mr. Watts said that the secondary-emission coefficient of lanthanum boride has not been measured. Mr. Beck said that his cathodes have a value 10 per cent higher than that for pure nickel, while Dr. Venema agreed that the value for the $L$ cathode is between $1 \cdot 0$ and $1 \cdot 5$. Dr. Huber discussed with Dr. Venema the reason for the former's failure to obtain good emission from bariumaluminate tungsten mixtures containing no additional reducing agent, and it appeared that the barium content and the sintering temperature are the important factors.

\section{BRITISH WEED CONTROL CONFERENCE, 1954}

$T$ HE second British Weed Control Conference was held at Harrogate during November 2-4 and was attended by four hundred delegates, including representatives from the British Colonies and most European countries. The Conference was organized on lines similar to those of the first one in 1953 ; that is, the emphasis was on the technology of weed control rather than on the underlying fundamental principles. The papers were divided into two broad classes, one concerned with general reviews of various aspects and the other with research reports on individual topics. The general papers again fell into two groups: the first related to the problems of commercial application, the efficiency of the available spraying equipment, the rotation of weed-killers, schemes for the approval of commercial products, and the legal aspects of spray damage; the second group contained surveys of modern developments in the use of herbicides and the associated problems of the dispersal of weed seeds and the role of mechanical cultivation.

Dr. W. G. 'Templeman (Jealott's Hill Research Station) reviewed the present position of herbicides in British agriculture. He pointed out that, although great advances have been made in the control of annual weeds in cereal crops, there still remain some relatively resistant and extremely important weeds, such as Avena fatua and Alopecurus agrestis, for which there are no adequate methods of control. $\mathrm{He}$ also emphasized that, while for many crops herbicidal applications are proving of great practical value, the position is far less satisfactory for root crops and many horticultural crops. In the past, too much stress has been laid on the total eradication of the weeds, and in many instances a better approach would be an endeavour to inhibit growth through the disorganization of the physiological processes. For example, 2,4,6-tribromophenylnitramine causes germinating seedlings to lose their capacity to react to tropic responses; but so far no compound with these characteristics has been discovered which is sufficiently selective.

While agreeing that herbicidal applications are playing an important part in British agricultural systems, Prof. H. G. Sanders (University of Reading) nevertheless felt that there is some danger that effective cultivation is not being fully appreciated. He was of the opinion that the hoe does more than kill the weeds and that its use in many circumstances is of direct benefit to the crop.

The organization of weed control investigations sponsored by the United States Department of 
Agriculture was outlined by Dr. C. Warren Shaw (Beltsville, Maryland). Apart from the screening of new compounds and some fundamental and development work at Beltsville, similar investigations are being carried out in all parts of the United States under the general direction of four regional coordinators. All this work in turn is linked with similar projects being undertaken by individual States. Dr. Shaw also outlined some of the modern developments which are taking place, particularly in relation to the value of such new herbicides as 2,3,6-trichlorobenzoic acid for the pre-emergence spraying of maize and sorghum, 2,4,5-trichlorophenoxypropionic acid for the control of woody plants in cotton-growing areas, 2,2-dichloropropionic acid for the eradication of graminaceous species, and the likely value of phenyl-substituted ureas for the control of weeds in sugarcane, pineapples, asparagus and possibly cotton. The other materials referred to included N-(1-naphthyl)phthalamic acid as a selective herbicide in cucurbitaceous crops and 3-amino1,2,4-triazole, which apart from its merit for defoliating cotton is likely to find a variety of uses as a herbicide.

An interesting new development in selective weed control was described by Prof. R. L. Wain (Wye College). In seeking to unravel the basic physiological actions of substituted phenoxyacetic acids, evidence has been obtained of the $\beta$ oxidation of $\omega$-phenoxyalkylcarboxylic acids. The alternation of biological activity with an increasing number of carbon atoms in the side-chain is only exhibited by some species. From these observations it is concluded that some species do not contain enzyme systems capable of breaking down the original compound to the parent phenoxyacetic acid. Thus, species which do not contain such enzyme systems will be resistant, while others which do will be susceptible. Pot and small-scale field experiments have confirmed this conclusion, and among the susceptible species are many common weeds, such as Urtica urens, Chenopodium album, Sinapis arvensis and Cirsium arvense, while resistant crops embrace red and white clovers, parsnips, celery, flax, maize, etc. A survey of the biological activities of $\gamma$-phenoxybutyric acids has also demonstrated that the position and number of methyl and chlorine atom substitutions in the benzene ring alter the properties of the molecule, which in turn alter the selective action between species. It is therefore evident that, with the introduction of compounds with odd numbers of carbon atoms in the side-chain, the value of substituted phenoxyacetic acids as selective herbicides will be extended to new crops.

Sir Edward Salisbury (Royal Botanic Garden, Kew) gave an account of the main factors relating to the persistence of weed seeds under British conditions and the principles of dispersal. Examples of the introduction and rate of spread of foreign species, such as Cardaria draba, were described. Once the initial introduction has taken place, the spread of the species is dependent upon a number of factors. For example, Veronica persica, which seeds very freely, has spread all over the country, whereas Veronica filiformis, which seeds but rarely because it is self-incompatible, is still highly localized in its distribution but may extend its area in the locality through vegetative propagation. In discussing the various agencies which lead to weed dispersal, it was pointed out that for birds the interval between ingestion and evacuation varies between thirty minutes and three hours or more, according to the species; thus, the rate of spread is greater where the seeds are readily taken by the larger birds, such as pigeons. Other aspects of seed dispersal by machinery and the laws governing injurious weed seeds and noxious weeds were discussed respectively by $\mathrm{F}$. Coleman (Cirencester) and J. A. MeMillan (National Agricultural Advisory Service).

The forty-six research reports presented at the Conference were considered in a number of groups, of which the most important related to weed control in horticulture, grassland, legumes, cereals, row crops and flax, while other aspects considered were the eradication of perennial grasses, the techniques of application both in greenhouse experiments and field trials, and the eradication of woody species under temperate and tropical conditions.

Apart from the selective control of weeds in peas and carrots, in other horticultural crops little progress has been made in the development of compounds which are selective when applied as a post-emergence spray, and most of the contributions bearing on horticulture reviewed the merits and defects of wellestablished practices. H. A. Roberts (National Vegetable Research Station) discussed the problems connected with the use of pre-emergence techniques and thought that, for contact pre-emergence applications, oil formulations containing pentachlorophenol are of considerable promise. For the control of dicotyledonous annual weeds in peas, dinitrosecbutylphenol is still the most widely used compound, both in Great Britain and on the Continent of Europe, although H. I. Petersen (Denmark) stated that good results have been achieved by using a mixture of dinitrosecbutylphenol and sodium 2-methyl-4-chlorophenoxyacetate. The potential value of isopropylphenylcarbamate and its 3 -chloroderivative for the selective elimination of wild oats (Avena spp.) and other weeds in peas was also dis. cussed. The best degree of control has been obtained by incorporating the herbicides in the soil before sowing the crop, but no final conclusions can yet be reached as to the direct action of these materials on peas.

The papers on the elimination of perennial weeds from grassland illustrated the complexity of the problem, and the value of the ecological approach in relation to the use of herbicides was emphasized by M. Norman (Grassland Research Station) and A. D. Q. Agnew (Bangor). Turning to other agricultural crops, I. S. Frederiksen (Denmark) and K. Fröier and H. Zienkiewicz (Sweden) advocated the use of mixtures of sodium dinitroorthocresylate and sodium methylchlorophenoxyacetate in fibre flax, while W. Q. Connold and E. I. Prytherch (National Agricultural Advisory Service) commented on the value of sulphuric acid for the control of annual weeds in Brassica crops.

Of the papers dealing with weed control in cereals, there was much interest in the contribution of Dr. P. Riepma (Holland), who described the results obtained when weed-free crops of autumn-sown wheat and rye were sprayed with dinitroorthocresol at various times during the winter period. In many instances, appreciable gains in yield were recorded, more particularly in rye, and the maximum gains occurred when spraying took place at the four- to fiveleaf stage of development. Dr. Riepma was of the opinion that these increases could not be explained in terms of the nitrogen contained in the herbicide, 
since the response was independent of the level of available nitrogen supply.

S. Andersen (Denmark) and Prof. B. Rademacher (Germany) gave accounts of experiments which sought to correlate weather conditions with the effects of substituted phenoxyacetic acids on cereals. J. D. Fryer and J. G. Elliott (Oxford) and T. C. Breese (Plant Protection, Ltd.) were in general agreement that, while wheat and barley cannot safely be sprayed until the plants reach the five-leaf stage, the optimum time to spray oats with 2-methyl4-chlorophenoxyacetic acid is in the one- to four-leaf stage. For perennial grasses the importance of the stage of development in relation to the timing of spray applications was illustrated in the contribution of R. S. L. Jeater (National Institute of Agricultural Botany), who described the complex inter-relationships between species, time of application and the abnormalities induced in the flower primordia and inflorescences.

Three papers were devoted to the means of controlling Agropyron repens; in Great Britain the emphasis has been on sodium trichloroacetate, while in Sweden, so Prof. H. Osvald and Dr. E. Aberg reported, comparisons are being made of sodium chlorate, sodium trichloroacetate and 2,2-dichloropropionic acid. Dr. H. P. Allen. (Plant Protection, Ltd.) described trials carried out in Malaya with phenyl-substituted ureas for the eradication of lalang (Imperata cylindrica). Neither 3(3,4-dichlorophenyl)1,1-dimethyl urea nor 3( $p$-chlorophenyl)-1,1-dimethylurea resulted in complete control of this species unless the rates of application excerded $80 \mathrm{lb}$. per acre. On the whole, better results were achieved when the treatment consisted of sodium trichloroacetate at 150-200 lb. per acre.

Prof. G. E. Blackman (Oxford) outlined the programme of investigations being conducted in East Africa by Dr. G. W. Ivens (Colonial Insecticide Research Unit, Tanganyika) in conjunction with the Agricultural Research Council's Unit at Oxford. The main object is to determine how far defoliants and arboricides can be used as means of eliminating tsetse flies through vegetation control. Experiments have shown that aircraft applications of the $n$-butyl ester of 2,4,5-trichlorophenoxyacetic acid are capable of defoliating, or even killing, a range of trees and shrubs found in communities which provide habitats for important species of tsetse fly. Besides applications from aircraft, other uses for such materials are being studied, and there is some evidence from Uganda that in high forest species of valueless trees can be eliminated by spraying the base of the tree with a suitable formulation of an arboricide, such as 2,4,5-trichlorophenoxyacetic acid.

\section{FEDERATION OF MATHEMATICS AND PHYSICS SOCIETIES OF YUGOSLAVIA \\ CONGRESS IN ZAGREB}

T

THE second congress of the Federation of Mathematics and Physics Societies of Yugoslavia was held in Zagreb during October 4-9, more than six hundred delegates attending. The congress considered a wide range of subjects - in the unanimous opinion of all present, too wide a rango-indicating, among other matter, the growth of mathematics and physics in Yugoslavia. Some of the questions the congress examined were the teaching of mathematics and physies in secondary schools; the teaching at universities ; and the organization of research in mathematics and physics. Eight sessions were devoted to research papers on mathematies, and nine to papers from the field of physics.

The present writer, being concerned mostly with nuclear physics, can give only a sample subject survey of papers in that field. One should bear in mind that this is the first time in the history of Yugoslavia that research papers in physics were reported at a nation-wide reunion of physicists. Altogether, a hundred and five research papers in physics were given, fifty-seven in the field of particle and nuclear physics, and forty-eight in optics, structure of crystals, geophysics, mathematical equipment, etc. A brief mention of the subjects of some of the papers in the field of nuclear and particle physics will indicate the range of interest. Theoretical research papers included one on the derivation of the nuclear forces from quantum field theory, one on the selection rules in meson theory and another two with Coulomb excitation of nuclei. Two communications dealt with the measurement of cosmic rays underground. A series of papers was on nuclear spectroscopy: beta decay of carbon-14, decay schemes of cæsium-133, crsium-134, tungsten185, etc. Other topics considered were the angular distribution in beryllium-9 reactions with deuterons, Auger spectrum of thorium B, the positive particles purported to be accompanying the bota decay of phosphorus-32, the duration of fission, etc. A number of papers dealt with neutron sources, neutron diffusion and calculations of distributions of neutron fluxes. The Stefan Institute of Ljubljana reported on the construction of a mass spectrograph, the Boshkovich Institute of Zagreb on the design of a cyclotron in the range of $20 \mathrm{MeV}$., and the Kidrich Institute of Belgrade on the functioning and improvement of the ion beam of a Cockcroft-Walton accelerator of $1.5 \mathrm{MeV}$.

At the final plenary session the congress adopted a series of decisions to be brought to the attention of the Yugoslav Government and the general public. Those pertaining to physics stressed the necessity of developing research in physics at the universities and urged greater material support of the Physics Department of the University of Belgrade. A systematic study was recommended for the development of physies in the eountry in the light of the development of its economy and the development of physics abroad. Especially underlined was the necessity for a more balanced development of physics research, with support for other branches of research in physics at least equal to that given to nuclear studies. There was considerable discussion, though no formal decision was talven, on the question of starting a central Yugoslav review of physics. At the congress an opinion was expressed that since physics in Yugoslavia is in the process of standing on its own feot, there should be, from an organization point of view, greater autonomy and independence of physics and mathematics activities in Yugoslavia. This point of view was reflected in the election of officers for the executive committee of the Federation, when Prof. G. Kurepa, a mathematician from Zagreb, was elected president, and Mr. A. Milojevich, a physicist, from Belgrade, as secretary for physics.
Stevan DediJer 